\title{
GPS- vs. DEM-Derived Elevation Estimates from a Hardwood Dominated Forest Watershed
}

\author{
L. Chris Kiser, J. Michael Kelly \\ Virginia Polytechnic Institute and State University, Blacksburg, USA \\ E-mail: \{lckiser,jmkelly\}@vt.edu \\ Received April 28, 2010; revised May 29, 2010; accepted June 3, 2010
}

\begin{abstract}
Topographic attributes are often used as explanatory variables when providing spatial estimates of various environmental attribute response variables. Elevation of sampling locations can be derived from global positioning systems (GPS) or digital elevation models (DEM). Given the potential for differences in elevation among these two data sources, especially in response to forest canopy cover, our objective was to compare GPS and DEM-derived elevation values during the dormant season. A non-parametric Wilcoxon test indicated GPS elevation was higher than DEM elevation with a mean difference of $6 \mathrm{~m}$. Linear regression analysis indicated that GPS and DEM elevation were well correlated $\left(\mathrm{R}^{2}=0.71, \mathrm{r}=0.84, \mathrm{p}<0.0001\right)$. Although elevation among the two data sources differed, the strong linear relationship allows for correction of elevation values in a predictable manner.
\end{abstract}

Keywords: Forest Canopy Cover, Linear Regression, Spatial Estimates

\section{Introduction}

Global positioning systems (GPS) are widely used in environmental research to identify locations of permanent sampling locations. Horizontal accuracy is suggested to be influenced primarily by GPS grade and canopy cover [1-4]. Spatial estimates of various environmental attribute response variables are widely developed using digital elevation model (DEM) derived topographic attributes as explanatory variables. Elevation derived from a DEM is an attribute typically used in this methodology. Alternatively, elevation determined by GPS may also be used in this type of analysis. Given the potential for differences in elevation among these two data sources, our objective was to compare GPS and DEM-derived elevation in a statistically rigorous manner on a typical hardwood forest site. GPS data for this analysis were collected in part in support of a recently published study on forest soil C and $\mathrm{N} \mathrm{[5]} \mathrm{and} \mathrm{are} \mathrm{reanalyzed} \mathrm{here.} \mathrm{The} \mathrm{utility} \mathrm{of} \mathrm{this}$ analysis results from a lack of studies that compare elevation derived from these two data sources.

\section{Methods}

\subsection{Site Description}

The Camp Branch Experimental Watershed is located in
Fall Creek Falls State Park on the Cumberland Plateau in Central Tennessee $\left(35^{0} 38^{\prime} \mathrm{N}\right.$ lat.; $85^{\circ} 18^{\prime} \mathrm{W}$ long.). The watershed is a 94 ha mixed hardwood forest. Permanent data points (Figure 1) were marked with steel posts as part of an earlier study [6]. GPS data were collected after leaf fall in November 2006 and canopy coverage was

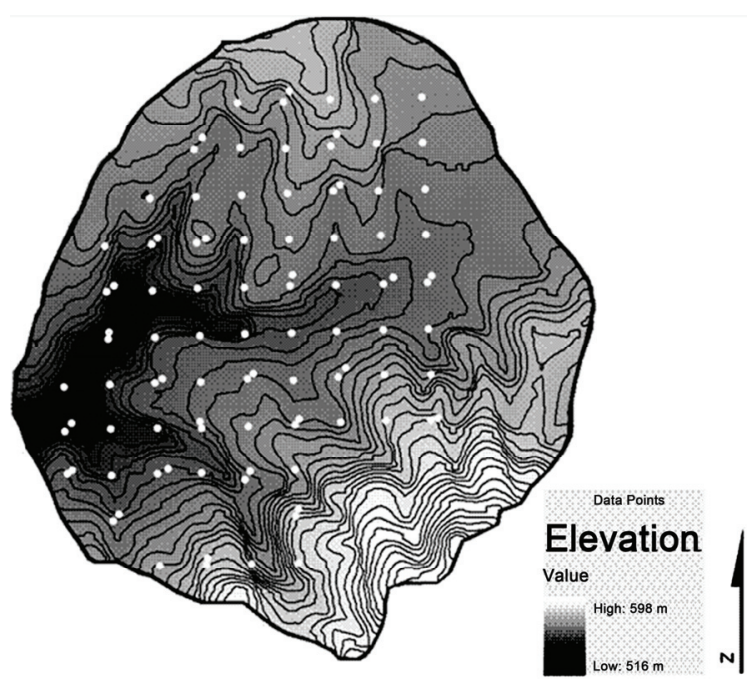

Figure 1. Elevation map of the 94 ha Camp Branch Experimental Watershed. Also shown are the 95 data points for which coordinates and elevation were determined. 
estimated to range from $15 \%$ to $25 \%$ during the GPS data collection period. Mean GPS elevation is $554 \mathrm{~m}$ and ranges from $532 \mathrm{~m}$ to $584 \mathrm{~m}$. Mean DEM-derived elevation is $548 \mathrm{~m}$ and ranges from $528 \mathrm{~m}$ to $567 \mathrm{~m}$.

\subsection{GPS Data}

Coordinates (UTM zone 16N; horizontal datum NAD83) and elevation of the 95 data points were collected in November 2006 with a mapping-grade Trimble GeoXT receiver (Trimble Navigation Ltd., Sunnyvale, CA, USA). Elevation of the data points was recorded as height above mean sea level (MSL) using the EGM96 geoid model. Data were post-processed with TerraSync v.2.52 (Trimble Navigation Ltd., Sunnyvale, CA, USA) using a continuously operating reference station (CORS) in Hartsville, TN located approximately 68 miles from the study area. After post-processing, a shapefile of the 95 data points was generated. Mean and standard deviation of the number of positional fixes was 15.0 and 9.8, respectively. Mean and standard deviation of maximum positional dilution of precision (PDOP) was 4.4 and 0.65 , respectively. Mean and standard deviation of horizontal precision was $1.3 \mathrm{~m}$ and $0.2 \mathrm{~m}$, respectively.

\subsection{Digital Elevation Model}

A level 2, 10-m resolution DEM of the watershed taken from the 7.5 minute Sampson, TN quadrangle was obtained from the U.S. Geological Survey's National Elevation Dataset (EROS, Sioux Falls, SD, USA). The horizontal datum of the DEM is NAD27 and the vertical datum is NAVD88.

\subsection{ArcGIS}

Both the GPS data point shapefile and the DEM were imported into ArcGIS v.9.2 (ESRI Inc., Redlands, CA, USA) and projected in UTM zone $16 \mathrm{~N}$ and NAD83 (Figure 1). Elevations of the 95 data points derived from the DEM were extracted for comparison with GPS elevations. The spatial analyst function was used to generate $10 \mathrm{~m}$ contour lines to aid in visualizing topographic features.

\subsection{Statistical Analysis}

Due to a non-normal mean difference, a non-parametric Wilcoxon procedure was used to test for differences among GPS and DEM-derived elevation (PROC NPAR1WAY, SAS v.9.1, SAS Institute Inc., Cary, NC, USA). The relationship of GPS to DEM-derived elevation was examined using simple linear regression (PROC REG, SAS v.9.1, SAS Institute Inc., Cary, NC, USA).

\section{Results and Discussion}

The Wilcoxon test indicated GPS elevations were larger than DEM-derived elevations $(Z=4.18, p<0.0001)$. Mean and standard deviation of the difference in elevation was $6 \mathrm{~m}$ and $5 \mathrm{~m}$, respectively. The difference in elevation ranged from $21 \mathrm{~m}$ to $-5 \mathrm{~m}$ (Table 1) and was not related to maximum PDOP, the number of positional fixes, and horizontal precision. Regression analysis indicated that GPS and DEM-derived elevation were well correlated $\left(\mathrm{y}=123.74+0.7665 \mathrm{x}, \mathrm{F}=226.2, \mathrm{R}^{2}=0.71, \mathrm{r}\right.$ $=0.84, \mathrm{p}<0.0001$ ) (Figure 2). Out of 95 data points, 4 fell outside the $95 \%$ prediction interval for the regression (Figure 2). Results indicate DEM-derived elevation of other data points within the study area can be adjusted with confidence when GPS-derived elevation is considered more representative of actual elevation thereby minimizing error propagation effects on accuracy of spatial estimates of environmental attribute response variables.

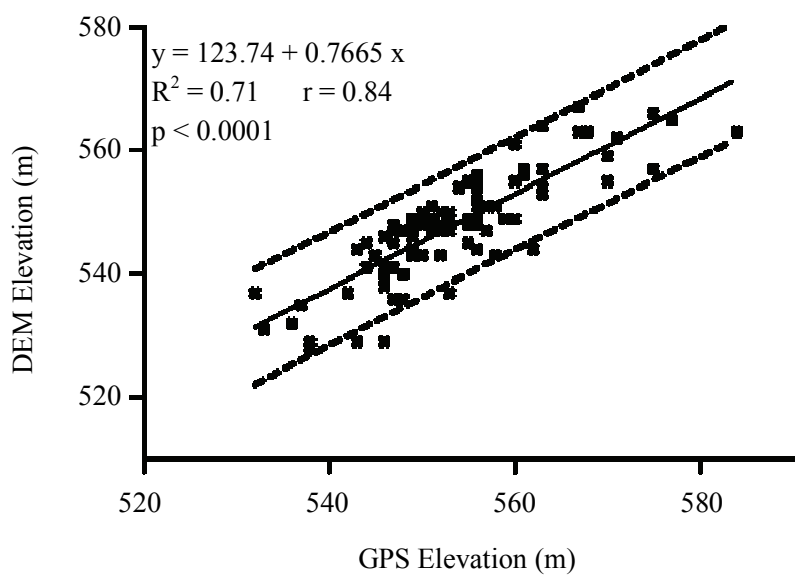

Figure 2. Scatterplot depicting DEM elevation as a function of GPS elevation. Linear regression equation, $\mathbf{R}^{2}, \mathbf{r}, \mathbf{p - v a l u e , ~ a n d ~}$ $\mathbf{9 5 \%}$ prediction interval are also shown. 
Table 1. GPS data collection parameters, GPS elevation, DEM elevation, and elevation difference for each of the 95 permanent data points on the Camp Branch Experimental Watershed.

\begin{tabular}{|c|c|c|c|c|c|}
\hline Maximum PDOP & Positional Fixes & Horizontal Precision & GPS Elevation & DEM Elevation & Elevation Difference \\
\hline 4.8 & 17 & 1.1 & 584 & 563 & 21 \\
\hline 3.3 & 14 & 1.2 & 575 & 557 & 18 \\
\hline 3.9 & 6 & 1.7 & 562 & 544 & 18 \\
\hline 4.3 & 10 & 1.3 & 546 & 529 & 17 \\
\hline 5.2 & 15 & 1.2 & 553 & 537 & 16 \\
\hline 5.8 & 28 & 1.1 & 570 & 555 & 15 \\
\hline 4.9 & 12 & 1.3 & 558 & 543 & 15 \\
\hline 3.3 & 13 & 1.0 & 543 & 529 & 14 \\
\hline 4.6 & 11 & 1.3 & 548 & 536 & 12 \\
\hline 4.7 & 6 & 1.3 & 577 & 565 & 12 \\
\hline 4.4 & 15 & 1.4 & 556 & 544 & 12 \\
\hline 5.1 & 10 & 1.5 & 560 & 549 & 11 \\
\hline 5.0 & 11 & 1.4 & 547 & 536 & 11 \\
\hline 5.7 & 14 & 1.3 & 570 & 559 & 11 \\
\hline 3.9 & 7 & 1.5 & 555 & 545 & 10 \\
\hline 4.4 & 15 & 1.4 & 538 & 528 & 10 \\
\hline 4.4 & 19 & 1.4 & 557 & 547 & 10 \\
\hline 4.6 & 17 & 1.0 & 559 & 549 & 10 \\
\hline 3.9 & 64 & 1.0 & 563 & 553 & 10 \\
\hline 5.1 & 11 & 1.6 & 563 & 554 & 9 \\
\hline 4.9 & 10 & 1.2 & 575 & 566 & 9 \\
\hline 4.5 & 4 & 1.8 & 571 & 562 & 9 \\
\hline 4.8 & 10 & 1.3 & 552 & 543 & 9 \\
\hline 3.3 & 6 & 1.3 & 538 & 529 & 9 \\
\hline 4.9 & 15 & 1.1 & 548 & 540 & 8 \\
\hline 4.9 & 10 & 1.2 & 556 & 548 & 8 \\
\hline 4.1 & 32 & 1.4 & 546 & 538 & 8 \\
\hline 4.3 & 18 & 1.5 & 550 & 543 & 7 \\
\hline 5.4 & 16 & 1.2 & 555 & 548 & 7 \\
\hline 4.2 & 10 & 1.6 & 555 & 548 & 7 \\
\hline 4.6 & 11 & 1.1 & 558 & 551 & 7 \\
\hline 5.0 & 16 & 1.4 & 556 & 549 & 7 \\
\hline 4.1 & 12 & 1.3 & 553 & 547 & 7 \\
\hline 4.7 & 10 & 1.6 & 563 & 557 & 6 \\
\hline 3.3 & 12 & 1.1 & 549 & 543 & 6 \\
\hline 4.9 & 15 & 1.1 & 547 & 541 & 6 \\
\hline 4.5 & 17 & 1.0 & 557 & 551 & 6 \\
\hline 4.2 & 15 & 1.3 & 555 & 549 & 6 \\
\hline 3.1 & 17 & 1.1 & 546 & 540 & 6 \\
\hline 3.8 & 8 & 1.0 & 549 & 543 & 6 \\
\hline 3.3 & 16 & 1.5 & 552 & 547 & 5 \\
\hline 2.5 & 11 & 0.9 & 560 & 555 & 5 \\
\hline 5.2 & 13 & 1.1 & 546 & 541 & 5 \\
\hline 4.8 & 12 & 1.2 & 556 & 551 & 5 \\
\hline 3.9 & 4 & 1.1 & 561 & 556 & 5 \\
\hline 4.0 & 10 & 1.1 & 552 & 547 & 5 \\
\hline 4.8 & 66 & 1.1 & 549 & 544 & 5 \\
\hline 3.9 & 10 & 1.2 & 568 & 563 & 5 \\
\hline 4.7 & 26 & 1.3 & 542 & 537 & 5 \\
\hline 3.4 & 10 & 1.3 & 551 & 547 & 4 \\
\hline 4.7 & 12 & 1.3 & 556 & 552 & 4 \\
\hline
\end{tabular}


Table 1 continued

\begin{tabular}{|c|c|c|c|c|c|}
\hline Maximum PDOP & Positional Fixes & Horizontal Precision & GPS Elevation & DEM Elevation & Elevation Difference \\
\hline 4.9 & 12 & 0.9 & 561 & 557 & 4 \\
\hline 3.2 & 10 & 1.2 & 552 & 548 & 4 \\
\hline 2.5 & 12 & 1.1 & 553 & 549 & 4 \\
\hline 4.1 & 12 & 1.1 & 536 & 532 & 4 \\
\hline 4.9 & 11 & 1.3 & 553 & 549 & 4 \\
\hline 4.7 & 10 & 1.2 & 567 & 563 & 4 \\
\hline 4.0 & 14 & 1.1 & 553 & 549 & 4 \\
\hline 5.4 & 12 & 1.4 & 553 & 550 & 3 \\
\hline 5.0 & 19 & 1.6 & 553 & 550 & 3 \\
\hline 4.6 & 11 & 1.2 & 549 & 546 & 3 \\
\hline 4.4 & 7 & 1.4 & 544 & 541 & 3 \\
\hline 4.7 & 12 & 1.1 & 551 & 548 & 3 \\
\hline 3.8 & 12 & 1.3 & 551 & 548 & 3 \\
\hline 4.2 & 10 & 1.6 & 553 & 550 & 3 \\
\hline 4.2 & 13 & 1.2 & 550 & 548 & 2 \\
\hline 4.8 & 22 & 1.0 & 545 & 543 & 2 \\
\hline 4.6 & 43 & 1.2 & 547 & 545 & 2 \\
\hline 4.4 & 20 & 1.2 & 551 & 549 & 2 \\
\hline 4.0 & 13 & 1.4 & 549 & 547 & 2 \\
\hline 5.2 & 7 & 1.4 & 537 & 535 & 2 \\
\hline 4.7 & 13 & 1.6 & 552 & 550 & 2 \\
\hline 4.1 & 12 & 1.4 & 550 & 548 & 2 \\
\hline 4.9 & 13 & 1.4 & 552 & 550 & 2 \\
\hline 4.8 & 10 & 1.0 & 556 & 554 & 2 \\
\hline 3.3 & 15 & 1.2 & 533 & 531 & 2 \\
\hline 4.7 & 10 & 1.1 & 548 & 547 & 1 \\
\hline 4.1 & 15 & 1.4 & 548 & 547 & 1 \\
\hline 4.7 & 16 & 1.2 & 556 & 555 & 1 \\
\hline 4.2 & 21 & 1.4 & 551 & 551 & 0 \\
\hline 4.9 & 12 & 1.7 & 549 & 549 & 0 \\
\hline 3.4 & 14 & 1.2 & 554 & 554 & 0 \\
\hline 4.2 & 14 & 0.9 & 555 & 555 & 0 \\
\hline 5.3 & 10 & 1.8 & 547 & 547 & 0 \\
\hline 4.9 & 12 & 1.2 & 551 & 551 & 0 \\
\hline 4.8 & 14 & 1.4 & 546 & 546 & 0 \\
\hline 4.8 & 22 & 1.4 & 567 & 567 & 0 \\
\hline 3.8 & 9 & 1.4 & 550 & 550 & 0 \\
\hline 4.5 & 23 & 1.4 & 556 & 556 & 0 \\
\hline 4.1 & 10 & 1.3 & 543 & 544 & -1 \\
\hline 3.6 & 10 & 1.3 & 544 & 545 & -1 \\
\hline 4.4 & 46 & 1.8 & 563 & 564 & -1 \\
\hline 4.9 & 15 & 1.4 & 547 & 548 & -1 \\
\hline 5.5 & 12 & 1.0 & 560 & 561 & -1 \\
\hline 4.8 & 23 & 1.3 & 532 & 537 & -5 \\
\hline
\end{tabular}

In a study that compared elevations from five mapping-grade Trimble GPS receivers with surveyed benchmark elevations [7], average absolute vertical errors of post-processed data among the receivers ranged from 0.8 $\mathrm{m}$ to $1.9 \mathrm{~m}$. The greatest effect on vertical error was canopy coverage. Vertical error of post-processed data was $0.2 \mathrm{~m}$ under open sky, $0.4 \mathrm{~m}$ under $50 \%$ canopy, and $3.3 \mathrm{~m}$ under $100 \%$ canopy. While the vertical error in our study was larger at $6 \mathrm{~m}$, the two studies are not directly comparable.

\section{Conclusions}

Results indicate that, under conditions specific to this study, 
although GPS elevation was overestimated compared to DEM-derived elevation, the relationship among these data sources was predictable and followed a well defined linear relationship. While the magnitude of the elevation difference among the two data sources was large for some of the data points, the strong linear relationship allows for correction of elevation values in a predictable manner. More generically, the results of this analysis indicate that potential differences in GPS and DEM derived elevation estimates will need to be considered when elevation related environmental attributes are analyzed and extrapolated spatially.

\section{References}

[1] M. G. Wing, A. Eklund and L. D. Kellogg, "ConsumerGrade Global Positioning System (GPS) Accuracy and Reliability," Journal of Forestry, Vol. 103, No. 4, June 2005, pp. 169-173.

[2] M. G. Wing and R. Karsky, "Standard and Real-Time Accuracy and Reliability of a Mapping-Grade GPS in a Coniferous Western Oregon Forest," Western Journal of
Applied Forestry, Vol. 21, No. 4, October 2006, pp. 222-227.

[3] M. G. Wing and A. Eklund, "Performance Comparison of a Low-Cost Mapping Grade Global Positioning Systems (GPS) Receiver and Consumer Grade GPS Receiver under Dense Forest Canopy," Journal of Forestry, Vol. 105, No. 1, January/February 2007, pp. 9-14.

[4] M. G. Wing, A. Eklund, J. Sessions and R. Karsky, "Horizontal Measurement Performance of Five MappingGrade Global Positioning System Receiver Configurations in Several Forested Setting," Western Journal of Applied Forestry, Vol. 23, No. 3, July 2008, pp. 166-171.

[5] L. C. Kiser, J. M. Kelly and P. A. Mays, "Changes in FoRest Soil Carbon and Nitrogen after a Thirty-Year Interval," Soil Science Society of America Journal, Vol. 73, No. 1, February 2009, pp. 647-653.

[6] J. M. Kelly, "Camp Branch and Cross Creek Experimental Watershed Projects," Report Nos. TVA/ONR-79/04, EPA-600/7-79- 053, 1979.

[7] M. G. Wing and A. Eklund, "Vertical Measurement Accuracy of Mapping-Grade Global Positioning Systems Receivers in Three Forest Setting," Western Journal of Applied Forestry, Vol. 23, No. 2, April 2008, pp. 83-88. 